\title{
Metrological characterisation of current transformers calibration unit for accurate measurement
}

\author{
Valentyn Isaiev $^{1}$, Oleh Velychko ${ }^{1}$ \\ ${ }^{1}$ SE "Ukrmetrteststandard", 4 Metrologichna, 03143 Kyiv, Ukraine
}

\begin{abstract}
The manuscript presents a method for the metrological characterisation of the commercial AC comparators used to calibrate current transformers. The theoretical basis for simulating the difference between two almost identical currents has been outlined, as well as the mathematical models for both a ratio error and a phase displacement has been derived. The measurement setup, consisting of conventional measuring instruments, has been described with a detailed presentation of its parameters. The sources of uncertainty have been distinguished and analysed with determining the current phase shift which led to a significant increase of relative measurement uncertainty. The simulation of measurement results was yielded in two ways: physically using a method presented and virtually using a Monte Carlo method. The second method confirmed that evaluating the measurement uncertainty through derived sensitivity coefficients is correct enough. The simulation results in the range from 1 to 1200 parts per million for both ratio error and phase displacement motivated the use of a comparator characterised through the proposed method for accurate measurement, especially for very low errors.
\end{abstract}

Section: RESEARCH PAPER

Keywords: Ratio error; Phase displacement; Measurement uncertainty; Calibration; Current transformer

Citation: Valentyn Isaiev, Oleh Velychko, Metrological characterisation of current transformers calibration unit for accurate measurement, Acta IMEKO, vol. 10, no. 2, article 3, June 2021, identifier: IMEKO-ACTA-10 (2021)-02-03

Section Editor: Ciro Spataro, University of Palermo, Italy

Received December 1, 2020; In final form April 14, 2021; Published June 2021

Copyright: This is an open-access article distributed under the terms of the Creative Commons Attribution 3.0 License, which permits unrestricted use, distribution, and reproduction in any medium, provided the original author and source are credited.

Corresponding author: Valentyn Isaiev, e-mail: black2001w@gmail.com

\section{INTRODUCTION}

The energy sector deals with electricity accounting for accurate settlements and monitoring the dynamic events for power quality assurance. The measuring instruments for phasor measurement [1], current conversion [2], [3] including current transformers (CT), are used all over the world. The accuracy of measuring instruments is steadily increasing and researchers continue to find the approaches for minimising the errors of equipment, in particular those of instrument transformers [4].

CTs have often an accuracy class of $0.2 \mathrm{~S}$ or $0.5 \mathrm{~S}$ according to the IEC standard and contribute to the accuracy of electricity accounting [5]. Almost all Countries have calibration laboratories that perform CT calibration, but not every laboratory is capable of calibrating a precision transformer with a measurement uncertainty of $50 \mu \mathrm{A} / \mathrm{A}$, and less. For example, Europe's leading PTB (Germany) laboratory declared measurement uncertainty in on-site calibrating the isolating CTs slightly less than $40 \mu \mathrm{A} / \mathrm{A}$ [6]. A sampling current ratio bridge for the calibration of CTs was developed at VSL (Netherlands) laboratory. The expanded uncertainty, declared by the developer, does not exceed $5 \mu \mathrm{A} / \mathrm{A}$ in magnitude and $5 \mu \mathrm{rad}$ in phase [7]. The researchers have also offered alternative approaches to determining the metrological characteristics of instrument transformers, such as the application of a quasi-balance technique using the virtual instrument [8], or low cost efficient digitiser [9], or a method based on the low-voltage reciprocity principle [10], or a calculation of the errors based on the excitation table [11].

\section{OVERVIEW AND PURPOSE}

A traditional technique of comparison with the reference CT using means of comparing remains predominant in the practice of most laboratories. The means of comparing the currents of both a working standard and a device under test (DUT) is an important component of the CT calibration system. The contributions of such devices used by National Metrology Institutes can be observed in the uncertainty budgets presented in the final Supplementary Comparison reports. In particular, the measurement uncertainties of means of comparing associated with PTB and FGUP "UNIIM" (Russia) are approximately 0.5 
part per million (ppm) [12]. The lowest contribution of the PTB's bridge has a level of several hundredths of $\mu \mathrm{A} / \mathrm{A}$ [13]. However, such a level of measurement uncertainty is reached only by some National Metrology Institutes, providing special conditions for calibration. The measurement uncertainty associated with the calibration of the current transformer bridge of GUM (Poland) is $5 \mu \mathrm{A} / \mathrm{A}$ in ratio error $(\mathrm{RE})$ and $14.5 \mu \mathrm{rad}$ in phase displacement (PD) [14].

SE "Ukrmetrteststandard", as a conformity assessment body, deals with both calibration and certification of measuring instruments, in particular CTs. Based on the available information, it can be argued that in today's calibration activities, CT manufacturers, testing labs, energy companies, and other related enterprises remain using commercially available means of comparing. When calibrating CTs with an accuracy class of $0.2 \mathrm{~S}$, the contribution to the total measurement uncertainty, obtained via the admissible tolerance, from the use of the measuring bridge can be more than $90 \%$ of the contribution of all the influencing variables when determining the $\mathrm{RE}$ value of $480 \mu \mathrm{A} / \mathrm{A}[15]$.

The design features and factors that affect the accuracy of one of the commercial automatic test devices are described in a developer article. In particular, it is stated that the accuracy of such a measuring instrument should not exceed 1 percent of the measurement result [16]. According to the user's guide of the CA507 comparator produced in Ukraine, the minimum intrinsic uncertainty is $2 \mu \mathrm{A} / \mathrm{A}$ when measuring RE. The analogous figure for PD measurement is $8.73 \mu \mathrm{rad}$.

The system for calibrating an automatic transformer test set using a current source with an operational amplifier was developed at the CMI (Czech Republic) [17]. The method, developed in TUBITAK UME (Turkey), intended for determining the errors of the CT test sets allows characterising these tools with a total uncertainty of $10 \mathrm{ppm}$ [18].

The creation of a convenient method for accurate metrological characterisation of comparison means for two almost identical alternating currents is the main task of the research work. Evaluating the uncertainty of measurements during its calibration using a derived mathematical model is also an objective of the paper.

To characterise the contribution of the work and to determine the place in the body of the instrumentation and measurement it should be noted that the mathematical models for determining the reference values of RE and PD allow checking the accuracy of CT calibration unit (i.e., comparator of two approximately equal currents) in an alternative way using the suitable measurement setup. According to the obtained models, it is easy to calculate the contribution of each input quantity and to evaluate an expanded uncertainty both in determining RE and in determining PD.

\section{THEORETICAL BASIS}

\subsection{Definition of current transformer errors}

According to world practice, it is customary to express the imperfection of a scale conversion of the CT using two characteristics: the current RE and the PD [19].

The current RE $\left(\varepsilon_{I}\right)$ following the IEC standard is the ratio of the product of the $I_{2}$ secondary current amplitude and the $K_{T}$ transformation ratio of CT to the amplitude of the $I_{1}$ primary current, i.e.:

$\varepsilon_{I}=100 \cdot\left(K_{T} \cdot I_{2}-I_{1}\right) / I_{1}$.
When the current flows successively through the primary windings of the DUT and reference transformer in the primary measuring circuit during calibration, one can consider the equation

$\varepsilon_{X}-\varepsilon_{S}=100 \cdot K_{T} \cdot\left(I_{X}-I_{S}\right) / I_{1}$,

where $I_{X}$ and $I_{S}$ are the secondary currents of DUT and working standard, respectively.

Since the error is usually obtained as a subtraction of the reference reading from the DUT reading and divided by the reference reading, the primary current should be expressed through the secondary current of a reference transformer. In this case, it is possible to express the RE of the DUT through the ratio of secondary currents. To do this, one should obtain the expression of primary current $I_{1}$ from equation (1) for the working standard:

$I_{1}=K_{T} \cdot I_{S} /\left(1+\varepsilon_{S} / 100\right)$.

Assuming the current RE of the reference transformer is zero (the case of an ideal transformer), one can transform the expression (2) to

$\varepsilon_{X}=100 \cdot\left(I_{X} / I_{S}-1\right)$.

For further analysis, it is more convenient to express the RE in relative units $(\mu \mathrm{A} / \mathrm{A})$; therefore, factor 100 will be removed from the expression (4).

The PD $(\Delta \varphi)$ between the $\varphi_{2}$ initial phase of the sinusoidal secondary current and the $\varphi_{1}$ initial phase of the primary current is the second component of the current scaling characteristic:

$\Delta \varphi=\varphi_{2}-\varphi_{1}$.

When the same current flows in the primary circuit of both the DUT and the working standard connected in series, the initial phase is the same for both devices, i.e.:

$\Delta \varphi_{X}-\Delta \varphi_{S}=\varphi_{2 X}-\varphi_{1 X}-\varphi_{2 s}+\varphi_{1 s}=\varphi_{2 X}-\varphi_{2 s}$.

If the PD of the reference transformer is zero (for an ideal transformer) then the PD between the primary and secondary DUT currents will be defined as the phase shift of the DUT secondary current relative to the secondary current of the reference transformer.

\subsection{Simulation of current difference}

The comparator produced in Ukraine is structured in such a way that its design has a measuring circuit where the current phasor is formed. This phasor is a result of subtracting two currents, i.e. DUT current and working standard current. This measuring circuit converts the specified current phasor and the output current phasor of the reference transformer into voltage drop during its passing through the certain measuring shunt. Furthermore, the measurement information is converted into digital codes by the analog-to-digital converter to calculate the ratio of the current difference phasor to the phasor of the reference transformer current.

In the typical operation of a comparator, there is a comparison of two currents. The current difference between two currents $I_{d}$ flows through the certain input circuit and the current IS of the reference transformer flows through the other measuring circuit. The DUT current $I_{X}$ is absent inside the device and the comparator indicates the value of the RE and PD.

Let us consider the case where the DUT current exceeds the amplitude of the reference transformer current, as shown in Figure 1. The angle $\beta$ is the angle between the phasors of $I_{d}$ and 


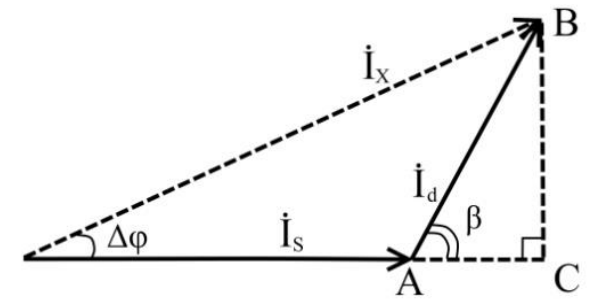

Figure 1. Interrelation between currents.

$I_{S}$ currents. To determine the characteristics of the interrelation between the DUT current and reference transformer current, it is necessary to determine the unknown elements of the triangle in Figure 1. The AC segment is determined as:

$$
\mathrm{AC}=I_{d} \cdot \cos \beta \text {. }
$$

The $\mathrm{BC}$ segment is determined as:

$$
\mathrm{BC}=I_{d} \cdot \sin \beta \text {. }
$$

The magnitude of the $I_{X}$ phasor is present in expression (4). Since this secondary current is not present in the circuit during simulation, its value must be expressed using expressions (7) and (8) through the equation:

$$
\begin{aligned}
& I_{X}=\sqrt{\left(I_{S}+\mathrm{AC}\right)^{2}+\mathrm{BC}^{2}}=\sqrt{\left(I_{S}+I_{d} \cdot \cos \beta\right)^{2}+I_{d}^{2} \cdot \sin ^{2} \beta} \\
& =\sqrt{I_{S}^{2}+2 \cdot I_{S} \cdot I_{d} \cdot \cos \beta+I_{d}^{2} \cdot \cos ^{2} \beta+I_{d}^{2} \cdot \sin ^{2} \beta}= \\
& \sqrt{I_{S}^{2}+2 \cdot I_{S} \cdot I_{d} \cdot \cos \beta+I_{d}^{2}}
\end{aligned}
$$

Substituting the expression (9) into equation (4), the following expression can be obtained to determine RE:

$$
\varepsilon_{X}=\sqrt{1+2 \cdot I_{d} / I_{S} \cdot \cos \beta+I_{d}^{2} / I_{S}^{2}}-1 .
$$

It should be mentioned that when considering the variant of the interrelation of $I_{d}$ and $I_{S}$ phasors, in case of excess in the amplitude of the current $I_{S}$, the sign before 2 changes to the opposite in expression (10).

Regarding the PD, it is determined from the ratio of the sides of the triangle in Figure 1:

$$
\tan \left(\Delta \varphi_{X}\right)=\mathrm{BC} /\left(I_{S}+\mathrm{AC}\right)
$$

The use of an inverse trigonometric function can define the expression for PD determination:

$$
\Delta \varphi_{X}=\operatorname{atan} \cdot\left[I_{d} \cdot \sin \beta /\left(I_{S}+I_{d} \cdot \cos \beta\right)\right] .
$$

When considering the variant of the interrelation of $I_{d}$ and $I_{S}$ phasors, in case of excess in the amplitude of the current $I_{S}$, no change occurs in expression (12). Since in this case, it is necessary to consider a right-angled triangle with a known angle of $(\pi-\beta)$.

\section{REALISATION OF METHOD}

\subsection{Measurement setup description}

The suggested technique allows calibrating the CT calibration unit by using the measuring scheme presented in Figure 2. Let us consider the elements of the measuring scheme for determining the relative current difference. A precision CT $(\mathrm{T})$ should be used as a stable $\mathrm{AC}$ current scaling element to calibrate the $\mathrm{AC}$ comparator. The secondary current is estimated to be smaller than a percent (or one-tenth of a percent) of the primary current. It means that CT secondary current simulates current difference $I_{d}$ between DUT and reference transformer. To simulate the low

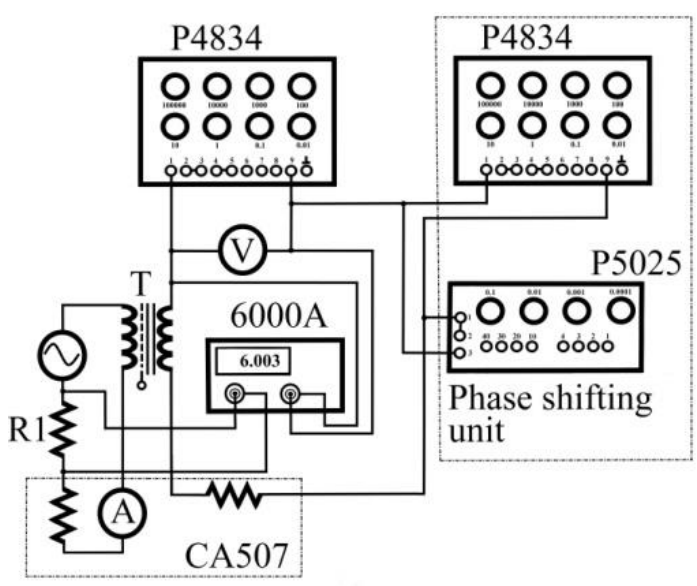

Figure 2. The electrical scheme of AC comparator calibration.

current difference, it may be necessary to introduce another stable CT for cascading into the measurement scheme in Figure 2. Thus, it is possible to achieve simulated error values of about $1 \mu \mathrm{A} / \mathrm{A}$, and even less.

The elements of the measuring circuit are connected in such a way that $I_{d}$ creates a voltage drop at the left P4834 resistance decade box as well as at the right measuring shunt of the CA507 comparator. A precision AC voltmeter is used to estimate the $I_{d}$ value through Ohm's law:

$I_{d}=U_{R D B} / R_{R D B}$,

where $U_{R B D}$ is a voltage drop caused by current $I_{d}$ that flows through the left P4834 resistance decade box; $R_{R B D}$ is a true value of the left P4834 resistance decade box.

To account for the branching of the current between the left P4834 resistance decade box and the precision voltmeter input circuit, the value of $I_{d}$ was also adjusted by the entry of the $K_{I M}$ branching factor.

The current flowing in the reference transformer circuit can be estimated using the CA507 built-in ammeter with worse uncertainty. If there is a need to decrease the total measurement uncertainty in the calibration of the AC comparator, a precision ammeter can be connected in series or the output voltage of the Fluke A40 precision shunt (R1) can be measured with a precision $\mathrm{AC}$ voltmeter. The contribution of using the CA507 comparator built-in ammeter to the combined standard uncertainty will be estimated below.

The CA507 right measuring shunt is an integral part of the calibrated comparator design and is used for extracting information on the difference between two input currents. The CT primary current flows through the CA507 internal ammeter, and also creates a voltage drop at both R1 current shunt and CA507 left shunt. The last shunt is used in the comparator design for extracting information on the current $I_{S}$ of the reference transformer.

A dual-channel Clarke-Hess $6000 \mathrm{~A}$ phase meter is needed to determine the angle $\beta$ between the currents flowing through the Fluke A40 current shunt and the left P4834 resistance decade box. Both the right P4834 resistance decade box and the P5025 capacitance box are connected in parallel to shift the angle $\beta$. It should be noted that the phase-shifting unit is only needed when simulating the PD, and may be absent during the simulation of the RE. Instead, it is possible to find the relation between the capacitance and the resistance of the phase-shifting unit when the angle $\beta$ is close to zero. 
Table 1. Estimates of quantities for setting RE.

\begin{tabular}{cccccc}
\hline $\begin{array}{c}\text { Current } \\
\text { phase } \\
\text { shift } \\
\left(^{\circ}\right)\end{array}$ & $\begin{array}{c}\text { Resistance } \\
\text { decade box } \\
\text { voltage } \\
\text { (V) }\end{array}$ & $\begin{array}{c}\text { Working } \\
\text { standard } \\
\text { circuit } \\
\text { current } \\
\text { (A) }\end{array}$ & $\begin{array}{c}\text { Resistance } \\
\text { decade box } \\
\text { value } \\
(\mathbf{k} \Omega)\end{array}$ & $\begin{array}{c}\text { Current } \\
\text { branching } \\
\text { factor }\end{array}$ & $\begin{array}{c}\text { RE } \\
(\mu \mathrm{A} / \mathrm{A})\end{array}$ \\
\hline 0.112 & 17.25 & 2.97 & 5 & 1.005 & 1167 \\
0.125 & 6.029 & 3.04 & 5 & 1.005 & 399 \\
0.131 & 1.8784 & 2.99 & 20 & 1.02 & 32.0 \\
0.136 & 0.7636 & 3.035 & 20 & 1.02 & 12.8 \\
0.145 & 0.709 & 2.99 & 40 & 1.04 & 6.17 \\
0.501 & 0.2526 & 3.02 & 60 & 1.06 & 1.47 \\
\hline
\end{tabular}

\subsection{Measurement setup characteristics}

According to the measurement scheme presented in Figure 2, a selection of the appropriate parameters of the circuit elements allowed us to simulate the RE and PD in the range of values from $1 \mathrm{ppm}$ to $1200 \mathrm{ppm}$. Table 1 summarises the estimates of the input quantities for which the RE values were obtained. It should be mentioned that the measurement setup allows us to vary the input quantities over a wide range and simulate a large number of RE values. Besides, the smallest measurement uncertainty can be achieved by setting the angle $\beta$ close to $0^{\circ}$ or $180^{\circ}$, and the worst uncertainty will be if the angle $\beta$ will be $90^{\circ}$. Table 2 presents the estimates of the input quantities for which the PD values were obtained.

The measurement setup allows us also to change the input quantities similarly to simulate the PD values. In this case, the smallest relative uncertainty of measurements can be achieved by setting the angle $\beta$ close to 90 or $270^{\circ}$, and the worst uncertainty will be when the angle $\beta$ will be 0 or $180^{\circ}$.

The measurement uncertainty, which the set of measuring instruments used can provide, is also a characteristic parameter of the measurement setup. Models (10) and (12) describe the dependence of simulated REs and PDs on variables whose uncertainty affects the total uncertainty of measurements of simulated quantities. Table 3 presents the simplified uncertainty budget for the RE of $32 \mu \mathrm{A} / \mathrm{A}$ and shows that the contribution of each input quantity for a given RE simulation point is comparable to each other.

Table 4 presents a simplified uncertainty budget for the simulated PD of $241 \mu \mathrm{rad}$ and shows that the contribution of each input quantity for a given PD simulation point is comparable to each other, as well as the previous case.

\section{ANALYSIS OF MEASUREMENT UNCERTAINTY}

\subsection{General points}

According to GUM 1995 [20], to determine the sensitivity coefficients of the input quantities, one must take the first partial

Table 2. Estimates of quantities for setting PD.

\begin{tabular}{cccccc}
\hline $\begin{array}{c}\text { Current } \\
\text { phase } \\
\text { shift } \\
\left.\mathbf{(}^{\circ}\right)\end{array}$ & $\begin{array}{c}\text { Resistance } \\
\text { decade box } \\
\text { voltage } \\
(\mathbf{V})\end{array}$ & $\begin{array}{c}\text { Working } \\
\text { standard } \\
\text { circuit } \\
\text { current (A) }\end{array}$ & $\begin{array}{c}\text { Resistance } \\
\text { decade box } \\
\text { value } \\
(\mathbf{k} \boldsymbol{\Omega})\end{array}$ & $\begin{array}{c}\text { Current } \\
\text { branching } \\
\text { factor }\end{array}$ & $\begin{array}{c}\text { PD } \\
(\boldsymbol{\mu r a d})\end{array}$ \\
\hline 139.82 & 4.103 & 1.035 & 2.2 & 1.0022 & 1167 \\
175.00 & 21.26 & 1.41 & 2.2 & 1.0022 & 603 \\
119.48 & 0.9949 & 2.995 & 1.2 & 1.0012 & 241 \\
119.04 & 1.482 & 3.065 & 3.2 & 1.0032 & 133 \\
173.52 & 0.3139 & 2.975 & 1.2 & 1.0012 & 10.0 \\
173.36 & 0.1766 & 3.055 & 3.2 & 1.0032 & 2.1 \\
\hline
\end{tabular}

Table 3. Characteristic of RE measurement uncertainty.

\begin{tabular}{cccc}
\hline $\begin{array}{c}\text { Source of } \\
\text { uncertainty }\end{array}$ & $\begin{array}{c}\text { Standard } \\
\text { uncertainty } \\
\text { estimate }\end{array}$ & $\begin{array}{c}\text { Sensitivity } \\
\text { coefficient }\end{array}$ & $\begin{array}{c}\text { Contribution to } \\
\text { combined standard } \\
\text { uncertainty }\end{array}$ \\
\hline$K_{I M}$ & $2.0 \cdot 10^{-3}$ & $3.1 \cdot 10^{-5}$ & $6.2 \cdot 10^{-8}$ \\
$U_{R D B}$ & $5.6 \cdot 10^{-3} \mathrm{~V}$ & $1.7 \cdot 10^{-5} \mathrm{~V}^{-1}$ & $9.6 \cdot 10^{-8}$ \\
$R_{R D B}$ & $100 \Omega$ & $1.6 \cdot 10^{-9} \Omega^{-1}$ & $1.6 \cdot 10^{-7}$ \\
$I_{S}$ & $0.01 \mathrm{~A}$ & $1.1 \cdot 10^{-5} \mathrm{~A}^{-1}$ & $1.1 \cdot 10^{-7}$ \\
6 & $7.9 \cdot 10^{-3}$ & $2.4 \cdot 10^{-7}$ & $1.9 \cdot 10^{-9}$ \\
\hline \multicolumn{3}{c}{ RE estimate } \\
$(\mu \mathrm{A} / \mathrm{A})$ & \multicolumn{2}{c}{ Expanded } \\
32 & \multicolumn{2}{c}{$0.45(\mathrm{k}=2)$} \\
\hline
\end{tabular}

derivatives for each input quantity. A detailed description of obtaining the sensitivity coefficients of the input quantities for the mathematical model (10) is given in the previous work [21]. As for the model (12), the expressions for determining the sensitivity coefficients are given in [22].

To verify the correctness of the expressions obtained, the MS Excel software was used to calculate the sensitivity coefficients $c\left(x_{i}\right)$ as the ratio of the increase of the transformed mathematical models with a substitution of current $I_{d}$ according to expression (13) to the small increase of each variable separately by the general expression:

$c\left(x_{i}\right)=\Delta f\left(x_{i}\right) / \Delta x_{i}$,

where $\Delta f\left(x_{i}\right)$ is a small increase of the corresponding mathematical model; $\Delta x_{i}$ is a small increase in the chosen input quantity.

The values obtained by the expression (14) were equal to the values calculated by the derived analytical expressions.

One of the factors in a distortion of the results of sinusoidal current measurements is the shape of the curve. During the study, there were doubts about providing a sinusoidal curve in the secondary winding of a current-scaling transformer $T$. That is because in simulating the transformer errors, the secondary winding of this transformer was loaded with resistance in the range from $1 \mathrm{k} \Omega$ to $60 \mathrm{k} \Omega$. To verify the curve of the sine wave at the terminals of the P4834 decade box, a voltage form was monitored using an oscilloscope since the secondary current flowed through the resistance decade box. The observation result is presented in Figure 3 in a form of a photograph.

In Figure 3 it can be seen that the secondary current of the transformer $\mathrm{T}$ (bottom left), which was more than $10 \mu \mathrm{A}$, flowed through the resistance decade box (top left). The comparator display (top right) shows that the current in the transformer primary winding was approximately $1 \mathrm{~A}$. The resistance value was $400 \mathrm{k} \Omega$ and the voltage at the terminals of the resistance decade box was controlled by a digital oscilloscope (bottom

Table 4. Characteristic of PD measurement uncertainty.

\begin{tabular}{|c|c|c|c|}
\hline $\begin{array}{l}\text { Source of } \\
\text { uncertainty }\end{array}$ & $\begin{array}{c}\text { Standard } \\
\text { uncertainty } \\
\text { estimate }\end{array}$ & $\begin{array}{l}\text { Sensitivity } \\
\text { coefficient }\end{array}$ & $\begin{array}{c}\text { Contribution to } \\
\text { combined standard } \\
\text { uncertainty }\end{array}$ \\
\hline$K_{I M}$ & $2.0 \cdot 10^{-3}$ & $2.4 \cdot 10^{-4}$ & $4.8 \cdot 10^{-7}$ \\
\hline$U_{R D B}$ & $3.0 \cdot 10^{-3} \mathrm{~V}$ & $2.4 \cdot 10^{-4} \mathrm{~V}^{-1}$ & $7.2 \cdot 10^{-7}$ \\
\hline$R_{R D B}$ & $6 \Omega$ & $2.0 \cdot 10^{-7} \Omega^{-1}$ & $1.2 \cdot 10^{-6}$ \\
\hline$I_{s}$ & $0.01 \mathrm{~A}$ & $8.1 \cdot 10^{-5} A^{-1}$ & $8.1 \cdot 10^{-7}$ \\
\hline$B$ & $7.9 \cdot 10^{-3}$ & $1.4 \cdot 10^{-4}$ & $1.1 \cdot 10^{-6}$ \\
\hline \multicolumn{2}{|c|}{$\begin{array}{l}\text { PD estimate } \\
(\mu \mathrm{rad})\end{array}$} & \multicolumn{2}{|c|}{$\begin{array}{c}\text { Expanded } \\
\text { uncertainty }(\mu \mathrm{rad})\end{array}$} \\
\hline \multicolumn{2}{|c|}{241} & \multicolumn{2}{|c|}{$4.1(k=2)$} \\
\hline
\end{tabular}




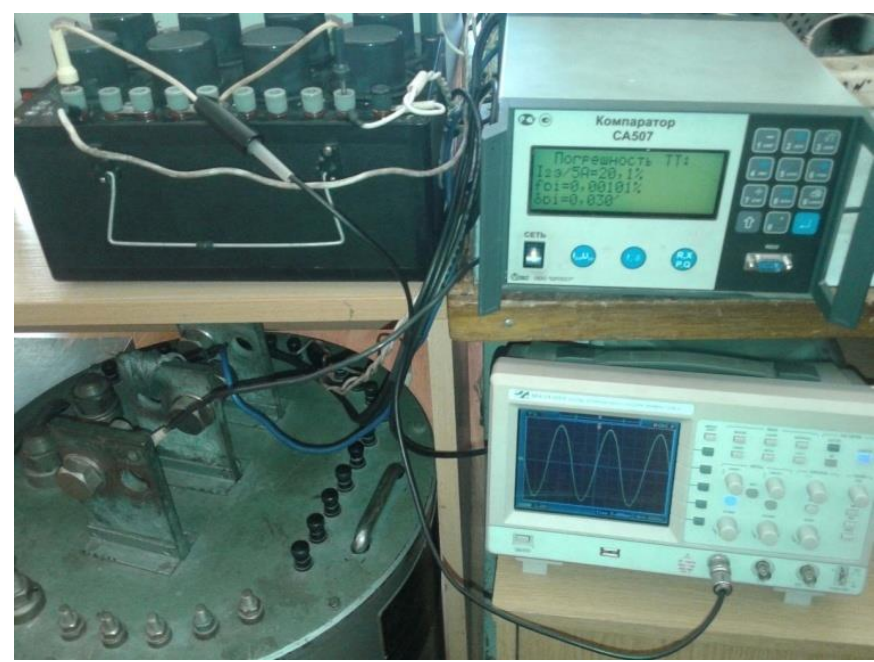

Figure 3. Observation of the shape of the voltage curve at the terminals of the P4834 decade box.

right). The display of the oscilloscope shows that the voltage form did not differ from the sine wave.

Thus, a load of several tens or hundreds of $\mathrm{k} \Omega$ on the secondary winding with a current of less than $0.1 \%$ of a rated current did not distort the shape of the secondary current. There was only an increase in the phase shift of the secondary current relative to the primary and the change in the simulated characteristics.

In a previous work, the P4834 decade box was characterised regarding the voltage phase shift at the terminals of this device relative to the flowing current [23]. Both the dependence of the phase shift on the set resistance and the corresponding measurement uncertainty was determined. It was found that the effect of the phase shift relative to the measured value, especially for the current phase shift of about $180^{\circ}$, was noticeable. This was reflected in the fact that the ratio of expanded measurement uncertainty to the result of PD measurement increased markedly. In contrast, with a phase shift between currents that differed from $180^{\circ}$ by more than $10^{\circ}$ no increase in relative uncertainty was observed.

\subsection{Ratio error measurement uncertainty}

Continuing the analysis, one can distinguish certain characteristic points when the simulated errors acquire values for which the measurement uncertainty far exceeds the error itself. This is due to the presence of a trigonometric component in both mathematical models. To find the characteristic points, the interrelation between input quantities was selected in a such position when the RE measurement result was $18 \mu \mathrm{A} / \mathrm{A}$. A series of the RE values at fixed values of all input quantities except for the current phase shift were modeled. The corresponding measurement uncertainty was also evaluated. The results of this simulation are presented graphically in Figure 4.

According to the model (10), Figure 4 shows that the RE (blue curve) acquires minimum value when the current phase shift gets the value of $90^{\circ}$. However, the absolute value of measurement uncertainty varies slightly over the whole range. The corresponding relative uncertainty of the measurements (red curve) in the current phase shift range from $0^{\circ}$ to about $60^{\circ}$ and from $120^{\circ}$ to $180^{\circ}$ remained at almost one level of about 2 percent despite the measured value in the simulation varied several dozen times. With a significant decrease in the simulated error, the percentage ratio of the almost constant measurement

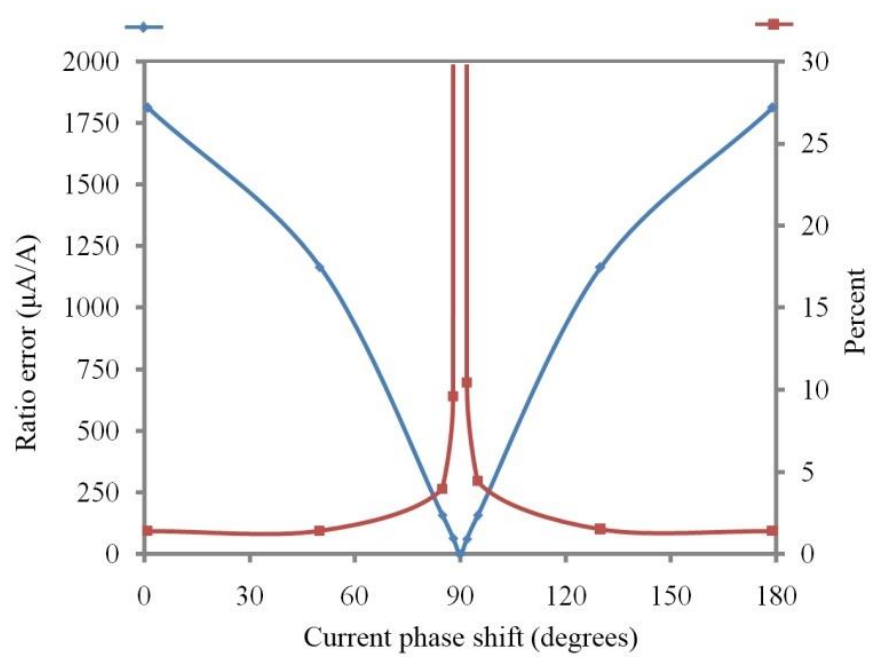

$\rightarrow$ Simulated ratio error depending on current phase shift

- Percentage ratio of uncertainty to measured ratio error

Figure 4. Simulation results of the ratio error depending on the current phase shift.

uncertainty to the specified error increased significantly, going to infinity at a point of $90^{\circ}$.

\subsection{Phase displacement measurement uncertainty}

To find the characteristic points in the PD simulation, the interrelation between the input quantities was chosen in such a position when the measurement result was $603 \mu \mathrm{rad}$. Several PD values were also simulated as well as the corresponding measurement uncertainty was estimated. The results of this simulation are presented graphically in Figure 5.

According to the model described by equation (12), Figure 5 shows that the PD (blue curve) acquired minimal value when a current phase shift of $0^{\circ}$ or $180^{\circ}$ was achieved. However, the absolute measurement uncertainty was almost the same since the measured quantities remained constant, only the phase shift between currents changed. The intrinsic uncertainty of the phase meter also remained almost constant, and the change of phase shift only affected the sensitivity coefficients. Since the measurand in the simulation varied 2-3 times in the current phase

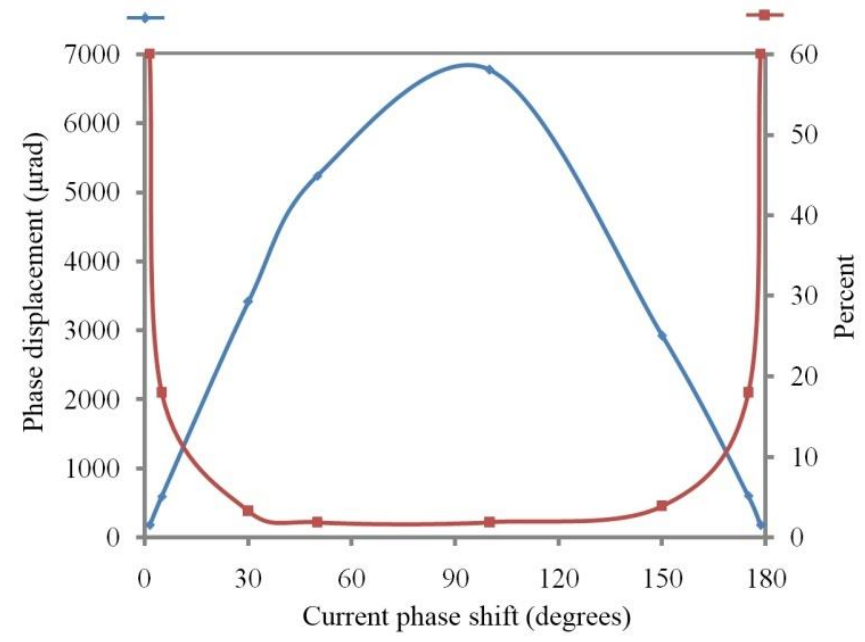

$\rightarrow$ Simulated phase displacement depending on current phase shift

- - Percentage ratio of uncertainty to measured phase displacement

Figure 5. Simulation results of the phase displacement depending on the current phase shift. 


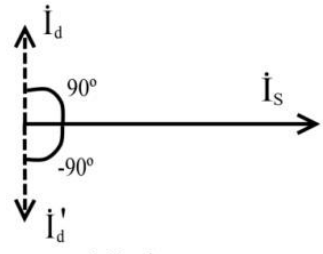

a) Ratio error

tends to zero b) Phase displacement tends to zero

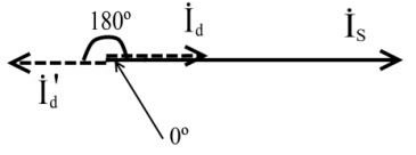

Figure 6. Interrelation between current phasors in simulating errors of current transformer.

shift range from $30^{\circ}$ to $150^{\circ}$, the corresponding relative measurement uncertainty (red curve) varied accordingly, reaching a minimum of about 2 percent. Nevertheless, with a significant decrease in the simulated error, the percentage ratio of the almost constant measurement uncertainty to the specified error increased significantly, going to infinity at points of 0 and $180^{\circ}$. The phenomena analysed above can be illustrated in a vector form as shown in Figure 6.

Option a) of Figure 6 shows that at a current phase shift close to $90^{\circ}$ or $-90^{\circ}$ when the small value of the difference between the $I_{X}$ and $I_{S}$ currents occurs, the whole error accounts for the PD (the amplitude of the $I_{X}$ and $I_{S}$ currents will be the same). Instead, option b) illustrates the opposite case where PD is absent and the whole current difference is related to the RE. Such points occur when the current phase shift is $0^{\circ}$ or $180^{\circ}$.

\section{SIMULATING MEASUREMENT RESULTS}

\subsection{Simulation using method proposed}

In Table 5 and Table 6 , the results of simulating the errors of CT, using the scheme depicted in Figure 2, are presented.

According to the specification of the CA507 comparator, the intrinsic uncertainty when measuring $\mathrm{RE}$ is determined in percentage by the formula

$$
u_{\mathrm{RE}}= \pm(0.005 \cdot \varepsilon+0.0002+0.0001 \cdot \Delta \varphi) \text {. }
$$

As can be seen from expression (15), the minimum uncertainty value cannot be less than $2 \mu \mathrm{A} / \mathrm{A}$.

According to the specification of the CA507 comparator, the intrinsic uncertainty in PD measurement is determined in minutes by the formula

$u_{P D}= \pm(0.005 \cdot \Delta \varphi+0.03+0.7 / 15 \cdot \varepsilon)$.

As can be seen in expression (16), the minimum uncertainty value cannot be less than $8.73 \mu \mathrm{rad}$. In Table 6 , the intrinsic uncertainty of CA507 is evaluated as 21.2 when measuring $605 \mu \mathrm{rad}$, and it exceeds the uncertainty when measuring $1132 \mu \mathrm{rad}$. One can see a clear upward trend in this characteristic with increasing measured value in formula (16). However, the

Table 5. Comparison of RE measuring data using CA507 comparator and calculated results.

\begin{tabular}{ccccc}
\hline $\begin{array}{c}\text { Current } \\
\text { (A) }\end{array}$ & $\begin{array}{c}c \\
\text { Comparator } \\
\text { readout }\end{array}$ & $\begin{array}{c}\text { Reference } \\
\text { value }\end{array}$ & $\begin{array}{c}\text { RE measurement } \\
\text { Comparator } \\
\text { readout }\end{array}$ & $\begin{array}{c}\text { Reference } \\
\text { value }\end{array}$ \\
\hline 2.975 & 1154 & 1167 & 8.3 & 9.2 \\
2.960 & 393 & 399 & 3.9 & 3.1 \\
2.993 & 31.3 & 32.03 & 2.2 & 0.45 \\
3.0356 & 12.5 & 12.84 & 2.1 & 0.21 \\
2.991 & 6.1 & 6.17 & 2.0 & 0.16 \\
3.022 & 0.6 & 1.47 & 2.0 & 0.11 \\
\hline
\end{tabular}
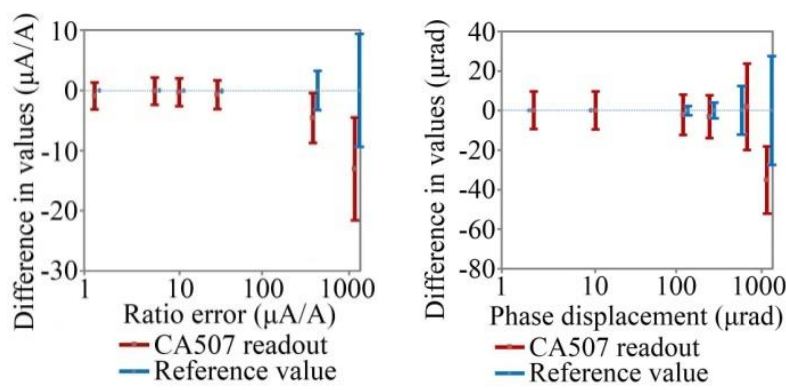

Figure 7. The difference in values obtained with evaluated measurement uncertainties.

interrelation between the RE and PD at the simulated measurement point led to an increase in intrinsic uncertainty due to the sufficiently strong effect of the amplitude component portion [24].

Figure 7 shows that the measurement uncertainty, evaluated according to GUM 1995 [20] for measured REs less than $100 \mu \mathrm{A} / \mathrm{A}$, has a large margin regarding test uncertainty ratio.

However, for the error above $200 \mu \mathrm{A} / \mathrm{A}$, measurement uncertainty increases markedly under conditions without additional measures such as stabilisation of the supply of the measuring circuit, determination of the voltmeter input impedance, etc.

In Figure 7, it could also be seen that the difference between the comparator readout and the reference value increases with the increase of the simulated error value.

\subsection{Simulation using Monte Carlo method}

To verify the correctness of the measurement uncertainty evaluation for the method proposed we decided to apply the Monte Carlo method during the simulation of the measurement results. The simulation was performed within the uncertainty of each input quantity (a case for RE of $32 \mathrm{ppm}$ is presented in Table 3, and for PD of $241 \mathrm{ppm}$ in Table 4). The simulation was yielded using the MS Excel software by generating the values with RANDBETWEEN function within the specified uncertainty intervals of the input quantities of both the model (10) for RE and the model (12) for PD, the number of error value observations was set to 30 , and the number of the values generated was set to 10 . The values of the simulation results, which differed as much as possible from values reported in Table 5 and Table 6 , are given in Table 7 for RE and in Table 8 for PD, as well as the average deviation.

Compared with the data obtained using the method proposed, the results obtained by the Monte Carlo method have a maximum deviation which did not exceed the uncertainty limitations specified above in Table 5 for RE and in Table 6 for PD. No simulated RE and PD values were obtained that would exceed the limits of the measurement uncertainty evaluated.

Table 6. Comparison of PD measuring data using CA507 comparator and calculated results.

\begin{tabular}{ccccc}
\hline $\begin{array}{c}\text { Current } \\
\text { (A) }\end{array}$ & $\begin{array}{c}c \\
\text { PD }(\mu \mathrm{rad}) \\
\text { Comparator }\end{array}$ & $\begin{array}{c}\text { Reference } \\
\text { value }\end{array}$ & $\begin{array}{c}\text { PD measurement } \\
\text { Comparator } \\
\text { readout }\end{array}$ & $\begin{array}{c}\text { Reference } \\
\text { value }\end{array}$ \\
\hline 3.051 & 1132 & 1167 & 16 & 26 \\
2.974 & 605 & 603 & 21 & 12 \\
3.065 & 238 & 241.1 & 10 & 4.1 \\
2.995 & 130.7 & 132.6 & 9.5 & 2.3 \\
1.417 & 10,2 & 10.0 & 8.9 & 1.1 \\
1.035 & 2.3 & 2.11 & 8.8 & 0.29 \\
\hline
\end{tabular}


Table 7. Results of simulating RE using Monte Carlo method.

\begin{tabular}{cccc}
\hline $\operatorname{RE}(\mu \mathrm{A} / \mathrm{A})$ & $\begin{array}{c}\text { Expanded } \\
\text { uncertainty } \\
(\boldsymbol{\mu} \mathrm{A} / \mathrm{A})\end{array}$ & $\begin{array}{c}\text { Maximum } \\
\text { deviation } \\
(\boldsymbol{\mu} \mathrm{A} / \mathrm{A})\end{array}$ & $\begin{array}{c}\text { Average } \\
\text { deviation } \\
(\boldsymbol{\mu} \mathrm{A} / \mathrm{A})\end{array}$ \\
\hline 1167 & 9.2 & 8.5 & 0.98 \\
399 & 3.1 & -2.6 & 0.46 \\
32 & 0.45 & -0.38 & -0.03 \\
12.8 & 0.21 & -0.11 & 0.02 \\
6.17 & 0.16 & 0.08 & -0.01 \\
\hline
\end{tabular}

Moreover, the average values of error estimates are an order of magnitude less than the measurement uncertainty evaluated.

Thus, the authors believe that the use of GUM 1995 to determine the expanded uncertainty for the method proposed allows us to evaluate this characteristic correctly enough.

\section{DISCUSSION}

One of the tasks of the calibration laboratory is to provide measurement uncertainty in the reference values 4 times less than that provided by the DUT. This paper proposes a method that allows achieving a measurement uncertainty of several tenths of $\mu \mathrm{A} / \mathrm{A}$ when calibrating a commercial CT calibration unit under ordinary laboratory conditions.

The calibration procedure described in the paper [25] involves reaching the condition when the error current is in phase with the standard current when determining the RE. To determine the PD, the shift of the error current by 90 degrees relative to the current through the standard current measurement circuit must be achieved. It should be noted that the proposed method allows characterising the commercial AC comparators without the requirement of in-phase currents or a $90^{\circ}$ angle shift due to applying the precision phase meter as stated in Section 4.1. As described in Sections 5.2 and 5.3, the proposed procedure can be applied for determining the errors of AC comparators in a wide range of changes in the current phase shift.

In the method described in [26] and [18], which has been mentioned in Section 2, an increment of simulated errors is limited to the discreteness of the PC-controlled three-phase power source, and a step of changing the ratio of turns of the electronically-compensated current comparator corresponds to $0.5 \%$. The use of a phase-shifting unit allowed the simulation of CT errors of almost any value using the method proposed. Due to the use of laboratory CT as a source, it is possible to generate the stable values of simulated errors, and cascading two such CTs allow us to simulate very small errors.

In Table 5 and Table 6 of Section 6.1, one can see that achieving the measurement uncertainty less than $1 \mathrm{ppm}$ in simulating the lowest error values is possible by the method presented. Moreover, the proposed analytical expressions make it easy to calculate both the magnitude of the reference values and the associated measurement uncertainty. The simulation results by the Monte Carlo method, which are shown in Table 7 and Table 8 , provide grounds to consider the evaluation of the measurement uncertainty to be correct. There are a large number of commercial comparators, and the user could check the accuracy of such a device using conventional precision measuring instruments through the proposed method. The measurement setup was tested several times using CA507 comparators. Also, the results can be extended to other types of comparators of almost identical currents, such as AITTS (India) or HGQA-C (China), which were characterised by the method that differs from the described one by the use of an oscilloscope
Table 8. Results of simulating PD using Monte Carlo method.

\begin{tabular}{cccc}
\hline PD $(\boldsymbol{\mu r a d})$ & $\begin{array}{c}\text { Expanded } \\
\text { uncertainty } \\
(\boldsymbol{\mu} \mathrm{rad})\end{array}$ & $\begin{array}{c}\text { Maximum } \\
\text { deviation } \\
(\boldsymbol{\mu} \mathrm{rad})\end{array}$ & $\begin{array}{c}\text { Average } \\
\text { deviation } \\
(\boldsymbol{\mu} \mathrm{rad})\end{array}$ \\
\hline 1167 & 26 & 23 & -2.8 \\
603 & 12 & 9.6 & 0.87 \\
241 & 4.0 & -3.1 & 0.43 \\
10.0 & 1.1 & -0.92 & -0.12 \\
2.11 & 0.29 & 0.25 & 0.05 \\
\hline
\end{tabular}

for determining the phase shift angle and has somewhat worse mathematical processing [21].

However, some issues need to be addressed. The analysis of the uncertainty budget (regarding Table 1 - Table 4 of Section 4.2) gives grounds for claiming that the total uncertainty can be significantly reduced also in the simulation of CT errors of about $1000 \mu \mathrm{A} / \mathrm{A}$ when additional measures are applied. The clarification of measurement uncertainty of a current (the use of precision ammeter), branching factor (the rigorous estimation of the input impedance of a voltmeter) can lead to a reduction of the total uncertainty of measurements.

The relationship between the amplitude and angular components of the simulated current difference has a great influence on the uncertainty estimation. The smaller the amplitude portion the smaller the measurement uncertainty of the angular component and vice versa. This is a direction for refining the measurement results.

The application of advanced technologies of data acquisition by replacement of voltmeter, phase meter by high-speed sample measuring devices with the subsequent automatic calculation of both reference values of errors and uncertainty of measurements should be also the direction of further improvement.

\section{CONCLUSIONS}

The presented measurement setup can be applied to simulate the errors of CTs in a wide range of values with a small step of changing the simulated characteristics.

The mathematical models derived for the determination of $\mathrm{RE}$ and PD in simulating these characteristics made it possible to obtain reference values for the characterisation of the CT calibration unit.

The measurement uncertainties evaluated in simulating the $\mathrm{RE}$ and PD allowed us to assume that the proposed method is advisable to apply in verifying the calibration unit for the laboratory CTs, especially in the range from 1 to $1000 \mu \mathrm{A} / \mathrm{A}$ ( $\mu \mathrm{rad})$.

The analysis of uncertainty sources allowed determining the value of the current phase shift between currents $\left(0^{\circ}, 90^{\circ}, 180^{\circ}\right.$, and $270^{\circ}$ ) which leads to a rapid increase of the total relative measurement uncertainty.

In determining the RE, the formation of the ratio of the currents, at which the PD goes to zero, allows minimising the contribution of the current phase shift.

\section{REFERENCES}

[1] P. Castello, C. Muscas, P. A. Pegoraro, S Sulis, A monitoring system based on phasor measurement units with variable reporting rates, ACTA IMEKO 7(4) (2018), pp. 62-69.

DOI: $\underline{10.21014 / \text { acta imeko.v7i4.585 }}$

[2] M. Crescentini, M. Marchesi, A. Romani, M. Tartagni, P. A. Traverso, Bandwidth limits in Hall effect-based current sensors, 
ACTA IMEKO 6(4) (2017), pp. 17-24.

DOI: $\underline{10.21014 / \text { acta imeko.v6i4.478 }}$

[3] V. Nováková Zachovalová, M. Šíra, P. Bednář, S. Mašláň, New generation of cage-type current shunts developed using model analysis, ACTA IMEKO 4(3) (2015), pp. 59-64.

DOI: $10.21014 /$ acta imeko.v4i3.250

[4] M. Cundeva-Blajer, Application of optimization methods for improved electrical metrology, ACTA IMEKO 5(3) (2016), pp. 915.

DOI: $10.21014 /$ acta imeko.v5i3.378

[5] IEC 61869-2:2012, Instrument transformers - Part 2: Additional requirements for current transformers, 2012, p. 144.

[6] E. Mohns, H. Latzel, C. Wittig, Power comparator based on-site calibration of isolating current transformers, MAPAN 24(1) (2009), pp. 67-72.

DOI: $10.1007 /$ s12647-009-0008-8

[7] H. E. van den Brom, G. Rietveld, E. So, Sampling current ratio bridge for calibration of current transducers up to $10 \mathrm{kA}$ with 5 ppm uncertainty, 29th Conference on Precision Electromagnetic Measurements (CPEM 2014), Rio de Janeiro, Brazil, 24-29 Aug. 2014.

DOI: $10.1109 /$ CPEM.2014.6898232

[8] N. M. Mohan, B. George, V. J. Kumar, Virtual Instrument for Testing of Current and Voltage Transformers, Proc. of 2006 IEEE Instrumentation and Measurement Technology Conference Proceedings, Sorrento, Italy, 24-27 April 2006, pp. 1163-1166. DOI: $10.1109 /$ IMTC.2006.328442

[9] N. George, P. V. Ooka, S. Gopalakrishna, An Efficient Digitizer for Calibration of Instrument Transformers, Proc. of 2018 IEEE 9th International Workshop on Applied Measurements for Power Systems (AMPS), Bologna, Italy, 2018, pp. 1-6. DOI: $10.1109 /$ AMPS.2018.8494842

[10] T. Yang, G. Zhang, X. Hu, System design of current transformer accuracy tester based on ARM, Proc. of 2013 IEEE 8 Conference on Industrial Electronics and Applications (ICIEA), Melbourne, Australia, 2013.

DOI: $10.1109 /$ ICIEA.2013.6566445

[11] CT analyzer user manual. Omicron Electronics GmbH, 2008. Online [Accessed 14 June 2021]

http://userequip.com/files/specs/6031/CTAnalyzer user $\% 20$ manual.pdf

[12] E. Mohns, Y. Sychev, G. Roeissle, Final report on COOMET.EM-S11: Supplementary bilateral comparison of the measurement of current transformers between UNIIM and PTB, Metrologia 51(1A) (2014), pp. 01013.

DOI: $10.1088 / 0026-1394 / 51 / 1 \mathrm{~A} / 01013$

[13] E. Mohns, G. Roeissle, S. Fricke, F. Pauling, An AC current transformer standard measuring system for power frequencies, IEEE Transactions on Instrumentation and Measurement 66(6) (2017), pp. 1433-1440. DOI: 10.1109/TIM.2017.2648918

[14] S. Harmon, L. Henderson, Final report EUROMET.EM-S11 on EUROMET projects 473 and 612: comparison of the measurement of current transformers (CTs), Metrologia 46(1A) (2009), pp. 01005.

DOI: $\underline{10.1088 / 0026-1394 / 46 / 1 \mathrm{~A} / 01005}$
[15] E. Mohns, P. Räther, Test equipment and its effect on the calibration of instrument transformers, Journal of Sensors and Sensor Systems 7(1) (2018), pp. 339-347.

DOI: $10.5194 /$ jsss-7-339-2018

[16] O. W. Iwanusiw, Microprocessor-based automatic instrument transformer comparator, IEEE Transactions on Instrumentation and Measurement 32(1) (1983), pp. 165-169. DOI: $10.1109 /$ TIM.1983.4315033

[17] K. Draxler, R. Styblíková, M. Ulvr, Use of a current source for calibrating an automatic transformer test set, Proc. of $16^{\text {th }}$ IMEKO TC4 Symposium "Exploring New Frontiers of Instrumentation and Methods for Electrical and Electronic Measurements", Florence, Italy, 22-24 September 2008. Online [Accessed 14 June 2021] https://www.imeko.org/publications/tc4-2008/IMEKO-TC42008-010.pdf

[18] H. Çayc1, An automatic system for current transformer test set calibrations, Proc. of $17^{\text {th }}$ IMEKO TC4 Symposium, Kosice, Slovakia, 8-10 September 2010, pp. 611-614. Online [accessed 14 June 2021] https://www.imeko.org/publications/tc19-2010/IMEKO_TC19-2010-125.pdf

[19] IEC 61869-1:2007, Instrument transformers -Part 1: General requirements, 2007, p. 134.

[20] JCGM 100:2008//GUM 1995 with minor corrections, Evaluation of measurement data - Guide to the expression of uncertainty in measurement, 2008. Online [Accessed 06 June 2021]. https://www.bipm.org/utils/common/documents/jcgm/JCGM $100 \quad 2008$ E.pdf

[21] V. Isaiev, Method of reference values defining for calibration of two alternating currents comparator with using oscilloscope, World Science 2(4 (32)) (2018), pp. 42-49.

[22] V. Isaiev, O. Velychko, Precise low-cost method for checking accuracy of current transformers calibration unit, Proc. of $24^{\text {th }}$ IMEKO TC-4 International Symposium, Palermo, Italy, 2020, pp. 406-410.

[23] V. Isaiev, S. Nosko, Power frequency characterization of resistance decade box for calibrating ac comparator, International Journal of Scientific and Engineering Research 10(10) (2019), pp. 1450-1456.

[24] V. Isaiev, O. Velychko, Y. Anokhin, Comparator effect on equivalence of results of calibrating current transformers, EasternEuropean Journal of Enterprise Technologies 5(101) (2019), pp. 6-15. DOI: $10.15587 / 1729-4061.2019 .177415$

[25] K. Draxler, J. Hlaváček, R. Styblíková, Calibration of instrument current transformer test sets, Proc. of 2019 International Conference on Applied Electronics (AE), Pilsen, Czech Republic, 2019, pp. 1-4.

DOI: $10.23919 / \mathrm{AE} .2019 .8866993$

[26] H. Çayc1, A complex current ratio device for the calibration of current transformer test sets, Metrology and Measurement Systems 18(1) (2011), pp. 159-164. DOI: $10.2478 / v 10178-011-0015-2$ 